This item was submitted to Loughborough's Research Repository by the author.

Items in Figshare are protected by copyright, with all rights reserved, unless otherwise indicated.

\title{
Large eddy simulation of fuel variability and flame dynamics of hydrogen- enriched nonpremixed flames
}

PLEASE CITE THE PUBLISHED VERSION

http://dx.doi.org/10.1016/j.fuproc.2012.07.019

PUBLISHER

(C) Elsevier

VERSION

AM (Accepted Manuscript)

LICENCE

CC BY-NC-ND 4.0

\section{REPOSITORY RECORD}

Ranga-Dinesh, K.K.J., X. Jiang, W. Malalasekera, and Anand Odedra. 2019. "Large Eddy Simulation of Fuel Variability and Flame Dynamics of Hydrogen-enriched Nonpremixed Flames". figshare.

https://hdl.handle.net/2134/10690. 
This item was submitted to Loughborough's Institutional Repository (https://dspace.lboro.ac.uk/) by the author and is made available under the following Creative Commons Licence conditions.

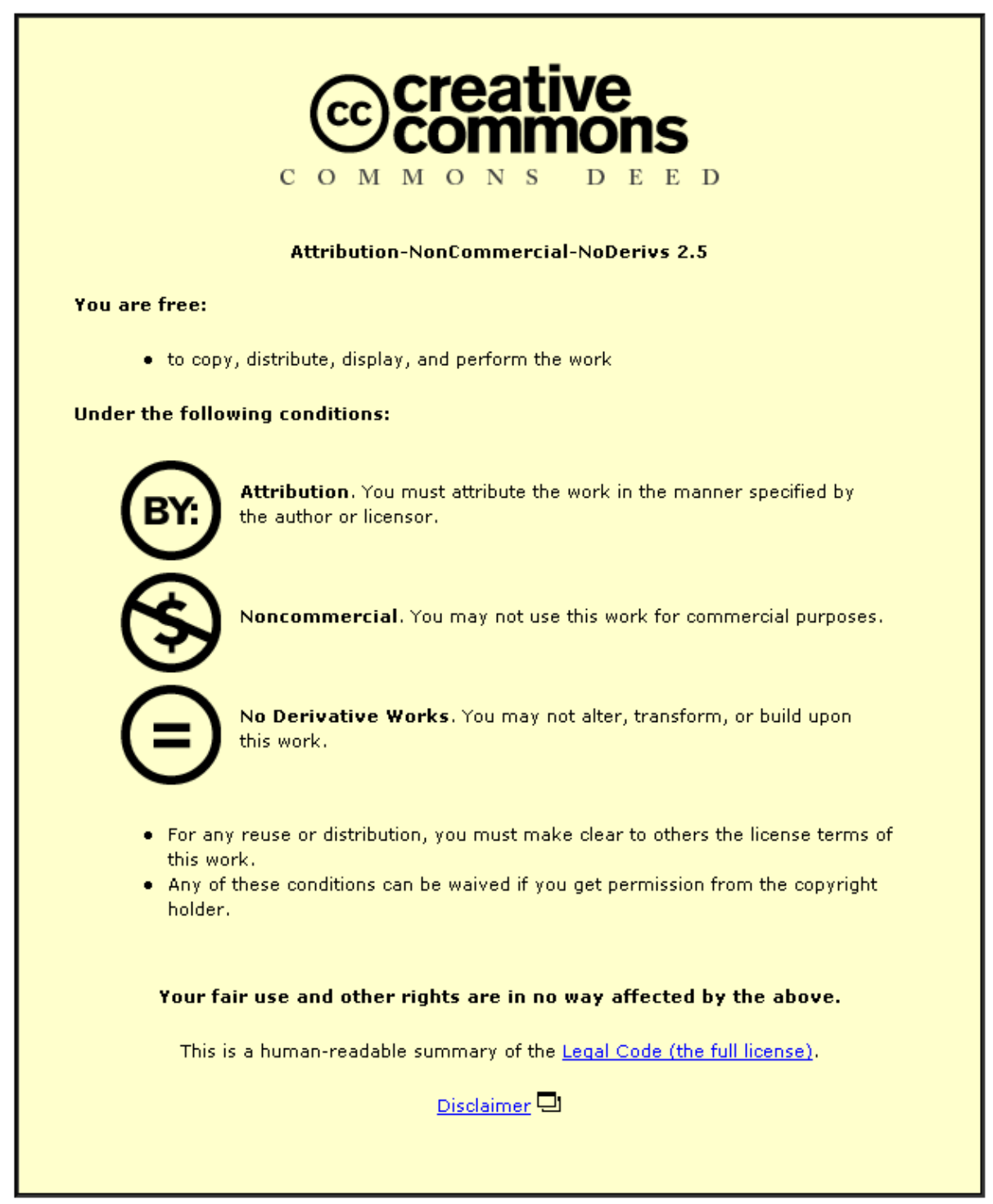

For the full text of this licence, please go to: http://creativecommons.org/licenses/by-nc-nd/2.5/ 


\title{
LARGE EDDY SIMULATION OF FUEL VARIABILITY AND FLAME DYNAMICS OF HYDROGEN-ENRICHED NONPREMIXED FLAMES
}

\author{
K.K.J.Ranga Dinesh ${ }^{1}$, X. Jiang ${ }^{1}$, W.Malalasekera ${ }^{2}$, A. Odedra ${ }^{3}$
}

1. Engineering Department, Lancaster University, Lancaster, Lancashire, LA1 4YR, UK.

2. Wolfson School of Mechanical and Manufacturing Engineering, Loughborough

University, Loughborough, Leicestershire, LE11 3TU, UK.

3. Hamworthy Combustion Engineering Limited, Fleets Corner, Poole, Dorset, BH17 0LA, UK.

Corresponding author: K.K.J.Ranga Dinesh, Engineering Department, Lancaster, Lancashire, LA1 4YR, UK.

Email: ranga.dinesh@lancaster.ac.uk. Tel: +44 (0) 1524594578

Revised Manuscript Prepared for the Journal of Fuel Processing Technology June 2012 


\begin{abstract}
In this study large eddy simulation (LES) technique has been used to predict the fuel variability effects and flame dynamics of four hydrogen-enriched turbulent nonpremixed flames. The LES governing equations are solved on a structured non-uniform Cartesian grid with the finite volume method, where the Smagorinsky eddy viscosity model with the localised dynamic procedure is used to model the subgrid scale turbulence. The conserved scalar mixture fraction based thermo-chemical variables are described using the steady laminar flamelet model. The Favre filtered scalars are obtained from the presumed beta probability density function approach. Results are discussed for the instantaneous flame structure, time-averaged flame temperature and combustion product mass fractions. In the LES results, significant differences in flame temperature and species mass fractions have been observed, depending on the amount of $\mathrm{H}_{2}, \mathrm{~N}_{2}$ and $\mathrm{CO}$ in the fuel mixture. Detailed comparison of LES results with experimental measurements showed that the predicted mean temperature and mass fraction of species agree well with the experimental data. Higher diffusivity and reactivity of $\mathrm{H}_{2}$ largely affect the flame temperature and formation of combustion products in syngas flames. The study demonstrates that LES together with the laminar flamelet model is capable of predicting the fuel variability effects and flame dynamics of turbulent nonpremixed hydrogen-enriched combustion including syngas flames.
\end{abstract}

Key Words: Syngas Combustion, Fuel Variability, Flame Dynamics, LES, Laminar Flamelet Model 


\section{Introduction}

Rising concentrations of greenhouse gases (GHG) in the atmosphere associated with energyrelated activities raise many challenges regarding present energy sources and use. Fundamentally, all fossil hydrocarbon resources are non-renewable, and thus it is vital to develop more effective and efficient ways to utilise these energy resources for sustainable development. Although the majority of world energy is supplied from the combustion of fossil fuels (petroleum, coal and natural gas), their dominant role in the GHG emissions such as carbon dioxide $\left(\mathrm{CO}_{2}\right)$ emissions necessitates the shifting towards a low carbon technology

[1]. However, since worldwide energy consumption is expected to grow further, it is necessary to continuously supply fuel for energy conversion and in the meantime to control GHG emissions [2]. Search for cleaner and alternative energy sources for low carbon energy technologies has recently become a major research topic worldwide.

Clean combustion as a means of energy conversion with limited environmental impact has a great potential in addressing major challenges in reducing GHG emissions, in association with new energy technologies such as carbon capture and storage which is one of the most effective approaches to reduce $\mathrm{CO}_{2}$ emissions [3]. As a result of interest in clean combustion, hydrogen $\left(\mathrm{H}_{2}\right)$ and syngas combustion (mainly mixture of $\mathrm{H}_{2}$ and carbon monoxide $\mathrm{CO}$ ) is receiving renewed and increased interest, as it can be flexibly generated from a wide range of solid fuels including coal, biomass and waste products [4] as well as from natural gas. Because of the large amount of resources available worldwide, especially coal in the U.S., Europe, and Asia, there is an interest in using hydrogen and syngas fuels to significantly cut GHG emissions. $\mathrm{H}_{2}$ production from fossil fuels and biomass involves conversion technologies such as reforming (hydrocarbons, oil), gasification, and pyrolysis 
(coal/biomass), while other conversion technologies such as electrolysis and photolysis can possibly be used when the source of $\mathrm{H}_{2}$ is water [5]. The synthesis gas or syngas is mainly a mixture of $\mathrm{H}_{2}$, $\mathrm{CO}$ and $\mathrm{N}_{2}$ with the exact compositions dictated by the type of fuel source (often fossil fuels, biomass or waste product) and the conversion technology used. The available hydrogen in syngas mixtures largely increases the rate of $\mathrm{CO}$ oxidation as radicals are propagated through faster hydrogen-related reactions [6-7]. The higher diffusivity and reactivity of hydrogen may lead to a higher flame temperature in combustion. In clean energy technologies based on syngas combustion, the fundamental issue is associated with the significant variation in syngas compositions that can influence flame dynamics including flame temperature, combustion products etc. Therefore design and development of syngas combustion for future clean energy systems need careful consideration of the effects of fuel variability on the flame properties such as flame dynamics, ignition and extinction limits [8].

Numerical simulation has the potential of closing the gap between theory and experiment and enabling dramatic progresses in combustion science and technology. LES has emerged as a promising numerical tool to simulate turbulent combustion problems corresponding to laboratory and practical scale configurations [9-10]. In the computation of complex combusting flows the unsteady three-dimensional (3D) nature of LES has many advantages for turbulence modelling over the classical Reynolds-averaged Navier-Stokes (RANS) approach. However in combustion LES, the chemical reactions usually occur well below the resolution limit of the LES filter width and consequently modelling is required to predict the chemistry. Combustion models which have been successfully used in the RANS context have been extended to LES to create sub-grid scale combustion models. For example, several groups employed equilibrium chemistry as a LES sub-grid model for the chemical reactions and obtained reasonable predictions for the thermo-chemical variables for 
laboratory scale nonpremixed jet flames [11-13]. The steady flamelet modelling concept [14] has been widely used in combustion LES, because of its simplicity and ability to predict minor species. LES with steady laminar flamelet model has been successfully applied to simulate the laboratory scale nonpremixed bluff-body flames and excellent comparisons with experimental measurements were obtained [9] [15]. However, the steady flamelet assumption is not strictly valid for flows with slow chemical and physical processes. The unsteady flamelet equations have to be used to account for such physical processes for nonpremixed jet flames [16]. The well known conditional moment closure model originally derived in the RANS context [17] has also been extended to LES and applied to nonpremixed flames [18]. The flamelet/progress variable approach, which has the potential to capture the local extinction, re-ignition and flame lift-off, has been applied in the context of LES [19]. Other approaches such as the linear eddy model [20] and the transported probability density function method [21] can also be used in nonpremixed combustion LES. Nevertheless, there is a lack of common knowledge on the general suitability of these models. In this context, experimental validation can play a significant role in assessing the model performance.

Interest in clean combustion relevant to syngas mixtures has inspired an extension of the existing numerical resources to investigate the comprehensive nature of hydrogen-enriched nonpremixed combustion. The current research was motivated by two observations: (1) the effects of fuel variability on flame dynamics in the context of clean combustion have not been fully understood; (2) there is a lack of systematic validation of LES results against laboratory flames of hydrogen-enriched combustion. Laboratory scale turbulent nonpremixed flames represent an excellent starting point for understanding the effects of fuel variability and flame dynamics of nonpremixed combustion. While the exact nature and relative importance of hydrogen-enriched combustion in more complex practical applications such as 
future low emission gas turbine combustors remain to be investigated, LES of simple laboratory scale syngas flames can provide valuable information for the design and development of clean combustion systems, based upon fundamental numerical data with comprehensive validation. The primary objective of the present modelling effort is to achieve accurate prediction of the hydrogen-enriched turbulent nonpremixed flames by validating against the experimental data and to obtain insights into the effects of fuel variability on the flame dynamics and combustion products in the context of LES. The next section discusses the simulated test cases. Sections 3 and 4 present the LES methodology and numerical computations. Section 5 presents the results and discussion and section 6 summarises the study and presents the conclusions.

\section{Simulated Test Cases}

Four different nonpremixed jet flames varying from $\mathrm{H}_{2}$-rich to $\mathrm{H}_{2}$-lean fuels including nitrogen and carbon monoxide mixtures have been considered. Three out of the four simulated flames have been selected from well-established experimental data archives [2225], and the fuel mixture of the fourth syngas flame is similar to one of the syngas fuels provided by BP Alternative Energy International Ltd. The flame conditions and their fuel compositions for all cases are presented in Table 1. Considering the fuel composition, four flames have been named as flame $\mathrm{H}\left(100 \% \mathrm{H}_{2}\right)$, flame $\mathrm{HN}\left(75 \% \mathrm{H}_{2}\right.$ and $\left.25 \% \mathrm{~N}_{2}\right)$, flame HNC1 $\left(30 \% \mathrm{H}_{2}, 30 \% \mathrm{~N}_{2}\right.$ and $\left.40 \% \mathrm{CO}\right)$ and flame HNC2 $\left(10 \% \mathrm{H}_{2}, 60 \% \mathrm{~N}_{2}\right.$ and $30 \%$ CO). Flames H, HN and HNC1 are from experiments conducted by Sandia, Sandia/ETHZurich and TNF Data Archives-DLR where complete details of the experimental data are given in [22-25] respectively. 


\section{LES Methodology}

In LES, the energy containing eddies are divided by a spatial filter and only large eddies are resolved while the small (sub-grid) eddies are modelled. In the present work, an implicit box (top-hat) filter was employed, which naturally fits into the finite volume formulation. A spatial filter is applied to separate the large and small scale structures. For a given function $f(x, t)$ the filtered field $\overline{f(x, t)}$ is determined by convolution with the filter function $G$

$\bar{f}(x)=\int_{\Omega} f\left(x^{\prime}\right) G\left(x-x^{\prime}, \bar{\Delta}(x)\right) d x^{\prime}$,

where the integration is carried out over the entire flow domain $\Omega$ and $\bar{\Delta}$ is the filter width, which varies with position. A number of filters are used in LES such as top hat or box filter, Gaussian filter, spectral filter. In the present work, a so called top hat filter (implicit filtering) having a filter-width $\bar{\Delta}_{j}$ proportional to the size of the local cell is used. In turbulent reacting flows large density variations occur, which are treated using Favre filtered variables, which leads to the transport equations for Favre filtered mass, momentum and mixture fraction:

$$
\begin{aligned}
& \frac{\partial \bar{\rho}}{\partial t}+\frac{\partial \bar{\rho} u_{j}}{\partial x_{j}}=0 \\
& \frac{\partial \bar{\rho} u_{i}}{\partial t}+\frac{\partial\left(\bar{\rho} u_{i} u_{j}\right)}{\partial x_{j}}=-\frac{\partial \bar{P}}{\partial x_{i}}+\frac{\partial}{\partial x_{j}}\left[\overline{2 \rho}\left(v+v_{t}\right)\left[\frac{1}{2}\left(\frac{\partial u_{i}}{\partial x_{j}}+\frac{\partial u_{j}}{\partial x_{i}}\right)-\frac{1}{3} \delta_{i j} \frac{\partial u_{k}}{\partial x_{k}}\right]\right] \\
& +\frac{1}{3} \frac{\partial}{\partial x_{j}}\left[\bar{\rho} \delta_{i j} \tau_{k k}\right]+\bar{\rho} g_{i} \\
& \frac{\partial \bar{\rho} \tilde{f}}{\partial t}+\frac{\partial}{\partial x_{j}}\left(\bar{\rho} \tilde{u}_{j} \tilde{f}\right)=\frac{\partial}{\partial x_{j}}\left[\bar{\rho}\left(\frac{v}{\sigma}+\frac{v_{t}}{\sigma_{t}}\right) \frac{\partial \tilde{f}}{\partial x_{j}}\right]
\end{aligned}
$$

In the above equations $\rho$ represents the density, $u_{i}$ is the velocity component in $x_{i}$ direction, $p$ is the pressure, $v$ is the kinematic viscosity, $f$ is the mixture fraction, $v_{t}$ is the turbulent viscosity, $\sigma$ is the laminar Schmidt number, $\sigma_{t}$ is the turbulent Schmidt number and $\tau_{k k}$ is the 
isotropic part of the sub-grid scale stress tensor. An over-bar describes the application of the spatial filter while the tilde denotes Favre filtered quantities. The laminar Schmidt number was set to 0.7 and the turbulent Schmidt number for mixture fraction was set to 0.4. Here the mixture fraction $f$ is defined as:

$$
f=\frac{s Y_{f}-Y_{o x}-Y_{o x, 2}}{s Y_{f, 1}+Y_{o x, 2}}
$$

Where, $Y_{f}$ is the local mass fraction of fuel, $Y_{o x}$ is the local mass fraction of oxidiser, $Y_{f, 1}$ is the fuel mass fraction in stream $1, Y_{o x, 2}$ is the oxidiser mass fraction in stream 2 and $s$ is the stoichiometric coefficient indicating the ratio of oxidiser mass and fuel mass which would be necessary for complete combustion. The mixture fraction $f$ defined in Eq. (5) is normalised in such a way that $f$ is equal to 1 in stream 1 and 0 in stream 2 . Finally to close these equations, the turbulent eddy viscosity $v_{t}$ in Eq. (3) and (4) has to be evaluated using a model equation.

The Smagorinsky eddy viscosity model [26] is employed to calculate the turbulent eddy $\operatorname{viscosity} v_{t}$. The Smagorinsky eddy viscosity model [26] uses a model parameter $C_{s}$, the filter width $\bar{\Delta}$ and strain rate tensor $S_{i, j}$ such that

$$
v_{t}=C_{s} \bar{\Delta}^{2}\left|S_{i, j}\right|=C_{s} \bar{\Delta}^{2}\left|\frac{1}{2}\left(\frac{\partial \tilde{u}_{i}}{\partial x_{j}}+\frac{\partial \tilde{u}_{j}}{\partial x_{i}}\right)\right|
$$

The model parameter $C_{s}$ is obtained using the localised dynamic procedure of Piomelli and Liu [27].

Combustion in nonpremixed systems can only take place when fuel and oxidizer are mixed at a molecular level. Turbulence mixing increases the scalar variance, while molecular diffusion 
forms a fuel/air mixture that enables chemical reactions to occur. In LES, chemical reactions occur at the sub-grid scales and therefore modelling is required for combustion chemistry. Here an assumed probability density function (PDF) for the mixture fraction is chosen as a means of modelling the sub-grid scale mixing. A $\beta$-PDF is used for the mixture fraction. The functional dependence of the thermo-chemical variables is closed through the steady laminar flamelet approach [14]. In the laminar flamelet model, the mixture fraction and the non-equilibrium parameter scalar dissipation rate are the two key parameters, which determine the thermochemical composition of the turbulent flame. In the flamelet approach a joint PDF for mixture fraction and scalar dissipation rate is used to determine the filtered values of temperature, density and species mass fractions. Here the filtered mixture fraction variance is modelled using the gradient transport model [12] and the filtered scalar dissipation rate is calculated using the model proposed in [28-29]. The flamelet calculations were performed using the Flamemaster code developed by Pitsch [30], incorporating the GRI 2.11 mechanism with detailed chemistry [31] for flames $\mathrm{H}$ and $\mathrm{HN}$ and the Drake's chemistry [32] for flames $\mathrm{HNC1}$ and $\mathrm{HNC} 2$. It is important to note that the present simulations were performed without the influence of differential diffusion (non-unity Lewis numbers). However, it is generally assume that the differential diffusion (non-unity Lewis numbers) is an important issue particularly for high hydrogen content fuels despite the fact that the differential diffusion does not play a greater role at sufficiently high Reynolds number which is the case for the simulated high hydrogen content flames, where the Reynolds number is close 10,000 .

\section{Numerical Computation}

The mathematical formulations for Favre filtered governing equations are numerically solved by means of a pressure based finite volume method using the LES code PUFFIN developed 
by Kirkpatrick et al. [33-34] and later extended by Ranga Dinesh et al. [35]. Spatial discretisation is achieved using a non-uniform Cartesian grid with a staggered cell arrangement. Second-order central difference is used for the spatial discretisation of all terms in both the momentum equation and the pressure correction equation. The diffusion terms of the mixture fraction transport equation are discretised using a second order central difference scheme (CDS). However, a CDS discretisation of convection would cause non-physical oscillations of the mixture fraction field, which is coupled with the momentum field through density. This means that wiggles in the mixture fraction would de-stabilise the solution of the velocity field. To overcome this problem, the present work employed "Simple High Accuracy Resolution Program" (SHARP) [36] for the convection of mixture fraction. An iterative time advancement scheme is used for the variable density calculation. First, the time derivative of the mixture fraction is approximated using the Crank-Nicolson scheme. The flamelet library yields the density and the filtered density field is calculated at the end of the time step. The new density at this time step is then used to advance the momentum equations. The momentum equations are integrated in time using a second order hybrid scheme. Advection terms are calculated explicitly using the second-order Adams-Bashforth scheme while diffusion terms are calculated implicitly using the second-order Adams-Moulton scheme to yield an approximate solution for the velocity field. Finally, mass conservation is enforced through a pressure correction step in which the approximate velocity field is projected onto a subspace of divergence free velocity field. Several outer iterations (8-10) are used to achieve the convergence for each time step and time steps are advanced with variable Courant number in the range of 0.3-0.6. The Bi-Conjugate Gradient Stabilized method with a Modified Strongly Implicit pre-conditioner is used to solve the system of algebraic equations resulting from the discretisation. 
In the current investigation, four hydrogen-enriched flame simulations have been performed using non-uniform Cartesian grids. The experimentally based pure hydrogen flame $\mathrm{H}$ [2223] was simulated with a domain of $800 \times 200 \times 200 \mathrm{~mm}$ in the $\mathrm{x}$ (axial direction), $\mathrm{y}$ and $\mathrm{z}$ directions respectively using non-uniform Cartesian grids with $200 \times 130 \times 130$ (approximately 3.4 million) cells. Since the other two experimentally based flames HN [24] and $\mathrm{HNC1}$ [25] involve relatively lower fuel jet velocity compared to flame $\mathrm{H}$, a domain with dimensions of $600 \times 200 \times 200 \mathrm{~mm}$ in the $\mathrm{x}$ (axial direction), $\mathrm{y}$ and $\mathrm{z}$ directions respectively was employed using the same number of computational cells. The BP syngas flame HNC2 was simulated using the same domain and grid resolution as $\mathrm{HNC1}$. The mean axial velocity distribution for the fuel inlet is specified using power low profile and turbulent fluctuation is generated from a Gaussian random number generator, which is then added to the mean axial profile such that the inflow has the same turbulence kinetic energy levels as those obtained from the experimental data [22-25]. A top hat profile is used as the inflow condition for the mixture fraction. To remove the non-physical artefacts of the initialisation, the simulation should evolve for a sufficiently long time before gathering any statistical results. This allows the flow field to fully develop and initial transients to exit the computational domain. The samples are only taken after the flow filed has fully developed. In this study to obtain statistically stationary results, time averaging of the variables were performed after 10 flowthrough-times $(\tau)$, which is defined here as the time for a fluid element to propagate through the computational domain, i:e. $\tau=L / U, L$ and $U$ are axial length of the computational domain and inlet bulk axial velocity respectively. All computations were carried out for a sufficient time to ensure that the solution has achieved a sufficient number of flow passes to provide good statistical data. The complete wall clock simulation time for the flame $\mathrm{H}$ was $0.05 \mathrm{~s}$ and it was $0.27 \mathrm{~s}$ for flames $\mathrm{HN}, \mathrm{HNC} 1$ and $\mathrm{HNC} 2$. 


\section{Results and Discussion}

In the present section results from LES of four different turbulent nonpremixed jet flames are presented. The four cases have different fuel mixture concentrations: from pure $\mathrm{H}_{2}$ (flame $\mathrm{H}$ ) [22-23] to $\mathrm{H}_{2}-\mathrm{N}_{2}$ mixture (flame $\mathrm{HN}$ ) [24] and $\mathrm{H}_{2}-\mathrm{N}_{2}-\mathrm{CO}$ mixtures (flames $\mathrm{HNC1}$ and HNC2) [25]. The intention was to study the fuel variability effects on the flame dynamics of pure $\mathrm{H}_{2}$, high $\mathrm{H}_{2}$ and low $\mathrm{H}_{2}$ turbulent nonpremixed syngas mixtures including the dilution of $\mathrm{N}_{2}$ and $\mathrm{CO}$. The analysis is focused on both instantaneous and time-averaged quantities such as temperature and combustion product mass fractions including comprehensive validation with well-established experimental data.

The first parameter of interest is the flame temperature. Figures 1-4 show the instantaneous 3D visualisation of the filtered flame temperature at several iso-surface values. These isosurfaces demonstrate the dynamic nature of the 3D hydrogen and hydrogen-enriched syngas flame structures. In nonpremixed combustion, the diffusive molecular mixing of fuel and air controls the chemical reactions and thus the flame temperature. The filtered 3D temperature fields demonstrate major structural changes between four flames in terms of the local flame topology, jet penetration as well as spreading. The pure $\mathrm{H}_{2}$ flame $\mathrm{H}$ exhibits less vortical structures compared to the relatively low $\mathrm{H}_{2}$ content flames $\mathrm{HN}, \mathrm{HNC} 1$ and $\mathrm{HNC} 2$. With the addition of $\mathrm{N}_{2}$, flame $\mathrm{HN}$ shows significant structural changes compared to the pure $\mathrm{H}_{2}$ flame $\mathrm{H}$, where flame $\mathrm{HN}$ is shorter but more vortical and more spread in the radial direction. Flame HNC1 again displays a different 3D flame structure compared to other flames for the considered iso-values. In Fig. 4, it can be seen that flame HNC2, where the iso-surface value of $1700 \mathrm{~K}$ is close to the maximum temperature in this case, is vortical but the iso-surface 
shows less radial spreading. In general, Figs.1-4 reveal that the level of $\mathrm{H}_{2}$ in the syngas mixture and its higher reactive behaviour largely affect the 3D flame structure as a result of the varying diffusivity levels, while the pure hydrogen flame $\mathrm{H}$ displays a much smoother topology and large penetration because of the large diffusivity and the higher jet velocity used to stabilize the flame in this case.

Figure 5 shows the cross-sectional (two-dimensional) instantaneous mixture fraction and flame temperature distributions of syngas flames $\mathrm{HN}, \mathrm{HNC} 1$ and $\mathrm{HNC} 2$ at $\mathrm{t}=0.2 \mathrm{~s}$ respectively. In these nonpremixed flames, combustion occurs in a thin layer in the vicinity of the stoichiometric surface and the cross-sections of the instantaneous variables can provide important information on the effects of fuel variability on the local flame dynamics. The instantaneous mixture fraction distributions between the $\mathrm{H}_{2}$-rich flame $\mathrm{HN}$ and $\mathrm{H}_{2}-\mathrm{N}_{2}-\mathrm{CO}$ flame $\mathrm{HNC} 1$ show slight differences at downstream regions, but the mixture fraction of the $\mathrm{H}_{2}$-lean and $\mathrm{N}_{2}$-rich flame $\mathrm{HNC} 2$ is more concentrated in the middle of the domain. This happens because of the differences in diffusivity associated with the amount of hydrogen available in the fuel. As seen in Fig. 5, the instantaneous temperature distributions of syngas flames $\mathrm{HN}, \mathrm{HNC} 1$ and $\mathrm{HNC} 2$ appear to be highly contorted corresponding to the mixture fraction distributions, showing significant structural changes near the centreline and downstream regions. The range of high temperature spots can be seen at both upstream and downstream regions for flame $\mathrm{HN}$. For flame $\mathrm{HNC1}$, the highest temperature spots are largely limited to the centreline region. For flame $\mathrm{HNC} 2$, less high temperature spots can be seen compared to other two flames. This occurs because of the different amount of hydrogen available in the fuel and the changes in diffusivity level. The variations of transport properties and chemistry associated with fuel variability can change the mixing rate and accordingly the chemical heat release and temperature distributions. The maximum instantaneous temperature 
of flames $\mathrm{H}, \mathrm{HN}, \mathrm{HNC1}$ and $\mathrm{HNC} 2$ are $2305 \mathrm{~K}, 2141 \mathrm{~K}, 2093 \mathrm{~K}$ and $1790 \mathrm{~K}$ respectively. This temperature difference is attributed to the different amount of combustible fuels available in the mixture. It is important to note that the instantaneous mixture fraction and temperature distributions including the 3D iso-surfaces shown in Figs. 1-4 reveal that syngas fuel composition variation not only leads to variations of flame temperature but also different fluid dynamic behaviours such as vortical structures in the reacting flow field.

In order to further analyse the flame dynamics and assess the LES predictions, the timeaveraged flame statistics are now discussed. The time-averaging sampling was carried out when the flame is statistically stable. Figures 6 and 7 show comparisons for the radial profiles of the mean mixture fraction and mixture fraction variance at different downstream axial locations. It is evident that the radial spread of the mixture fraction is slightly under predicted at the near field of the jet for considered flames. Despite this slight discrepancy, the agreement between calculations and measurements is good at other downstream axial locations. The mixture fraction variance is slightly under predicted for $\mathrm{HN}$ flame, but shows reasonable comparisons with the experimental data for both $\mathrm{H}$ and $\mathrm{HNC1}$ flames. Overall predictions of mixture fraction and its variance, however, show reasonably good agreement at all other locations.

The comparison of the predicted mean temperature field is shown in Fig. 8. For the $\mathrm{N}_{2}$ diluted flame $\mathrm{HN}$, the peak flame temperature is lower than that of the pure $\mathrm{H}_{2}$ flame, but similar to flame HNC1. Numerical results for the HNC2 flame are also shown for comparison purposes with the $\mathrm{HNC} 1$ data, where it should be noted that experimental data is not available for the HCN2 flame. The high temperature in flame $\mathrm{H}$ is mainly because of the high level of diffusivity and reactivity of $\mathrm{H}_{2}$. However the higher molar heating value of $\mathrm{CO}$ also 
increases the flame temperature, consequently flames $\mathrm{HN}$ and $\mathrm{HNC1}$ have similar peak temperatures. The mean temperature of the three syngas flames $\mathrm{HN}, \mathrm{HNC} 1$ and $\mathrm{HNC} 2$ is lower than that of the pure $\mathrm{H}_{2}$ flame $\mathrm{H}$ due to the fuel variability. The temperature of flame HNC2 is much lower than HNC1 because of the differences in fuel compositions. In Fig. 8, it can be seen that the mean temperature is slightly under-predicted at $\mathrm{x}=253,338 \mathrm{~mm}$ for flame $\mathrm{H}$ and at $\mathrm{x}=231.6 \mathrm{~mm}$ for flame $\mathrm{HNC} 1$, which appears as a result of discrepancy of the radial spread of the mean mixture fraction. Although the mixture fraction predictions are satisfactory at most axial locations, the calculated flame temperature appears to deviate from the experimental measurements. This is associated with the turbulent combustion modelling especially for the flame $\mathrm{HNC1}$ because the $\mathrm{H}_{2}-\mathrm{N}_{2}-\mathrm{CO}$ mixture may have a lower flame speed compared to $\mathrm{H}_{2}$ and the diffusive based molecular mixing rate and heat release may not have been well modelled. The flame can be subjected to different shear effects associated with the fuel variability, while the selected flamelets with thermo-chemical properties extracted from the corresponding strain rates should not be completely accurate enough. In addition, the steady flamelet assumption should not be perfectly valid for variable syngas fuel compositions such as the HNC1 flame, which could have resulted in these discrepancies. However, given the large density gradient between $\mathrm{H}_{2}$ and air, the comparison of calculated temperature field with experimental data for flames $\mathrm{H}, \mathrm{HN}$ and $\mathrm{HNC} 1$ are reasonable at most of the axial locations. The mean temperature profiles of the four cases indicate that the amount of $\mathrm{H}_{2}$ in the fuel mixture largely affects the flame dynamics while the LES is generally capable of quantitatively predicting the flame temperature distributions.

The next parameters of interest are the combustion products. The comparisons for the mass fractions of $\mathrm{H}_{2}$ and $\mathrm{H}_{2} \mathrm{O}$ are shown in Figs. 9-10, while those of $\mathrm{CO}$ and $\mathrm{CO}_{2}$ are shown in 
Fig. 11. The trends of mass fractions of $\mathrm{H}_{2} \mathrm{O}$ are consistent with those of temperature showing different peak values for all four flames. The highest value of $\mathrm{H}_{2} \mathrm{O}$ mass fractions is seen for flame $\mathrm{H}$ and the values are gradually decreasing for $\mathrm{HN}, \mathrm{HNC} 1$ and $\mathrm{HNC} 2$ with lower amount of $\mathrm{H}_{2}$ availability in the syngas fuel mixture. In order to examine the combustion products such as the mass fractions of $\mathrm{CO}$ and $\mathrm{CO}_{2}$ for flames $\mathrm{HNC1}$ and HNC2, the comparison between LES results and experimental data of mass fractions of CO and $\mathrm{CO}_{2}$ for flame $\mathrm{HNC} 1$, and LES results for flame HNC2 are shown in Fig. 11. For syngas combustion, the addition of $\mathrm{CO}$ in the fuel leads to both unburnt $\mathrm{CO}$ and burnt $\mathrm{CO}_{2}$ in the combustion products. LES data agrees well with measurements of CO, but slightly underpredicts the $\mathrm{CO}_{2}$, indicating that there might be some scope for combustion model improvements. Compared to flame $\mathrm{HNC1}, \mathrm{HNC} 2$ shows lower mass fraction of $\mathrm{CO}$ as a result of $10 \% \mathrm{CO}$ reduction in the fuel mixture. However, mass fraction of $\mathrm{CO}_{2}$ does not show large differences between the two flames. In general, the predictions of mass fractions of species using the laminar flamlet model are reasonably good and provide useful information on their formation with respect to the amount of $\mathrm{H}_{2}, \mathrm{~N}_{2}, \mathrm{CO}$ in the syngas fuel mixture.

\section{Conclusions}

The characteristics of hydrogen-enriched nonpremixed turbulent flames have been investigated using large eddy simulations. A hydrogen flame, hydrogen-nitrogen flame and two hydrogen-nitrogen-carbon monoxide flames were studied in detail by considering validation against well-established experimental data. The fuel variability effects have been 
investigated by examining both the instantaneous flame structures and time-averaged flame properties.

The overall effects of $\mathrm{H}_{2}$ with and without diluents in nonpremixed jet flames has been inferred. The presence of $\mathrm{H}_{2}$ in syngas introduces a multitude of complexities to the nonpremixed turbulent flame processes. It has been found that the high diffusivity of $\mathrm{H}_{2}$ can alter the diffusion flame structure including the local flame topologies and the mixing process. Due to the high reactivity and diffusivity of hydrogen, the flame dynamics of simulated $\mathrm{H}, \mathrm{HN}, \mathrm{HNC} 1$ and $\mathrm{HNC} 2$ cases display several important differences including the flame surface topology and flame temperature. The influences of $\mathrm{CO}$ and $\mathrm{N}_{2}$ as dilutions of the fuel mixture on the flame temperature and mass fractions of the combustion products are evident. It has been found that the fuel variability not only affects the flame temperature, but also plays a key role in the formation of the vortical structures in the flow fields.

Since addition of $\mathrm{H}_{2}$ tends to increase nitric-oxide $\left(\mathrm{NO}_{\mathrm{X}}\right)$ emissions due to an increase in reaction temperature, there is a clear need for further investigation of $\mathrm{H}_{2}$-rich and $\mathrm{H}_{2}$-lean syngas combustion to examine the $\mathrm{NO}_{\mathrm{X}}$ formation characteristics. Furthermore, it is also important to note that strain rate which depends on the amount of $\mathrm{H}_{2}$ in the fuel mixture might play a key role in determining the flame peak temperature and the radical product mass fractions. Therefore further systematic numerical and experimental studies of the effects of strain rate and differential diffusion on hydrogen-enriched combustion should be considered, which could also be vital to identify local flame extinctions. Furthermore, the effects of swirl on flame dynamics of hydrogen-enriched combustion should be investigated as most practical combustion systems including clean gas turbine combustion will be developed in the 
presence of swirl, which plays a significant role in enhancing the mixing. In addition, improvements on turbulent combustion modelling of hydrogen-enriched combustion are needed, although the current predictions showed acceptable agreements. Clearly more work especially improvements in modelling of $\mathrm{H}_{2}$-rich and $\mathrm{H}_{2}$-lean syngas combustion for various engineering applications oriented at cleaner combustion needs to be pursued in future efforts.

\section{Acknowledgement}

This research is funded by the UK EPSRC grant EP/G062714/2. The syngas mixture composition of HNC2 flame was provided by the BP Alternative Energy International Ltd. 


\section{References}

1. T. Nakata, D. Silva, M. Rodionov, Application of energy system models for designing a low- carbon society, Prog. in Energy Combust. Sci., 37 (4) (2011) 462-502.

2. A. Ghoniem, Needs, resources and climate change: Clean and efficient conversion technologies, Prog. in Energy and Combustion Science, 37 (2011) 15-51.

3. V. Rai, D. Vicor, M. Thurber, Carbon capture and storage at scale: Lessons from the growth of analogous energy technologies, Energy Policy, 38 (2010) 4089-4098.

4. T. Lieuwen, V. Yang, R. Yetter, Synthesis gas combustion: Fundamentals and applications, CRC Press Taylor and Francis Group, FL, USA, 2010.

5. K. Liu, C. Song, V. Subramani, Hydrogen and syngas production and purification technologies, John Wiley Inc. New Jersey, USA, 2010.

6. R.S. Brokaw, Ignition kinetics of the carbon monoxide-oxygen reaction. Proc. Combust. Inst.,11 (1967) 1063.

7. R.A. Yetter, F.L. Dryer, H. Rabitz, A comprehensive reaction mechanism for carbon monoxide/ hydrogen/oxygen kinetics, Combust. Sci. Tech., 79 (1991) 97.

8. M. Chaos, M.P. Burke, J.Yiguang, J, F.L. Dryer, Syngas chemical kinetics and reaction mechanisms, Synthesis gas combustion: fundamentals and applications, edited by $\mathrm{T}$. Lieuwen, Yang, R. Yetter, CRC Press, Taylor and Francis Group, Boca Raton, FL, USA, 2010.

9. R. Venkatramanan, H. Pitsch, Large eddy simulation of bluff body stabilized nonpremixed flame using a recursive filter refinement procedure, Combust. Flame, 142 (2005) $329-347$.

10. T. Poinsot, D. Veynante, Theoretical and numerical combustion, R.T. Edwards Int., PA 19031, USA, 2005. 
11. A.W. Cook, J.J. Riley, A subgrid model for equilibrium chemistry in turbulent flows, Phys. Fluids, 6(8) (1994) 2868-2870.

12. N. Branley, W.P. Jones, Large eddy simulation of turbulent non-premixed flames, Combust. Flame, 127 (2001) 1917-1934.

13. H. Forkel, J. Janicka, Large eddy simulation of a turbulent hydrogen diffusion flame, Flow Turbulence Combust, 65 (2000) 163-175.

14. N. Peters, Laminar diffusion flamelet models in non-premixed turbulent combustion, Prog. Energy Combust. Sci., 10 (1994) 319-339.

15. A. Kempf, R.P. Lindstedt, J. Janika, Large eddy simulation of bluff body stabilized nonpremixed flame, Combust. Flame 144 (2006) pp. 170-189.

16. H. Pitsch, H. Steiner, Large eddy simulation of turbulent methane-air diffusion flame, Phy. Fluids, 12(10) (2000) 2541-2554.

17. R.W. Bilger, Conditional moment closure for turbulent reacting flows, Phys. Fluids, A (5) (1993) 436-444.

18. S. Navarro-Marteniz, A. Kronenburg, Conditional moment closure for large eddy simulations, Flow Turb. Combustion, 75 (1-4) (2005) 245-274.

19. C.D. Pierce, P. Moin, Progress variable approach for LES of non-premixed turbulent combustion, J Fluid Mech., 504 (2004) 73-97.

20. P.A. Mcmurtry, S. Menon, A. Kerstein, A linear eddy subgrid model for turbulent reacting flows: application to hydrogen air combustion, Proc Combust Inst, 25 (1992) 271278.

21. S.B. Pope, PDF methods for turbulent reacting flows, Prog. Energy Combust. Sci., 11 (1985) 119-145.

22. R.S. Barlow, C.D. Carter, Raman/Rayleigh/LIF measurements of nitric oxide formation in turbulent hydrogen jet flames, Combust. Flame, 97 (3-4) (1994) 261-280. 
23. R.S. Barlow, C.D. Carter, Relationships among nitric oxide, temperature and mixture fraction in hydrogen jet flame, Combust. Flame, 104 (1996) 288-299.

24. International Workshop on Measurements and Computation of Turbulent Nonpremixed Flames, http://www.ca.sandia.gov/TNF/simplejet.html, TNF Data Archives- $\mathrm{H}_{2} / \mathrm{N}_{2}$ Jet flames (DLR-Stuttgart) .

25. R.S. Barlow, G.J. Fiechtner, C.D. Carter, J.Y. Chen, Experiments on the scalar structure of turbulent CO/H2/N2 jet flames, Combustion and Flame, 120 (2000) 549-569.

26. J. Smagorinsky, General circulation experiments with the primitive equations. M. Weather Review, 91 (1963) 99-164.

27. U. Piomelli, J. Liu, Large eddy simulation of channel flows using a localized dynamic model, Phy. Fluids 7 (1995) 839-848.

28. S.S. Girimaji, Y. Zhou, Analysis and modelling of subgrid scalar mixing using numerical data, Phys. Fluids 8, (1996) 1224-1236.

29. A.W. Cook, J.J. Riley, Subgrid scale modelling for turbulent reactive flows, Combust. Flame, 112 (1998) 593-606.

30. H. Pitsch, A C++ computer program for 0-D and 1-D laminar flame calculations, RWTH, Aachen, 1998.

31. C.T. Bowman, R.K. Hanson, D.F. Davidson, W.C. Gardiner, V. Lissianki, G.P.Smith, D.M. Golden, M. Frenklach, M. Goldenberg, GRI 2.11, 2006.

32. M.C. Drake, R.J. Blint, Relative importance of nitric oxide formation mechanisms in laminar opposed-flow diffusion flames, Combust. Flame, 85 (1991) 185-203.

33. M.P. Kirkpatrick, S.W. Armfield, J.H. Kent, A representation of curved boundaries for the solution of the Navier-Stokes equations on a staggered three-dimensional Cartesian grid, J. of Comput. Phy., 184 (2003) 1-36. 
34. M.P. Kirkpatrick, S.W. Armfield, A.R. Masri, S.S. Ibrahim, Large eddy simulation of a propagating turbulent premixed flame, Flow, Turb. Combust., 70 (1) (2003) 1-19.

35. K.K.J. Ranga Dinesh, K.W. Jenkins, M.P. Kirkpatrick, W. Malalasekera, Identification and analysis of instability in non-premixed swirling flames using LES, Combust. Theory Model, 13 (6) (2009) 947-971.

36. B.P. Leonard, SHARP simulation of discontinuities in highly convective steady flows, NASA Tech. Memo., Vol. 100240, 1987. 


\section{Table}

Table 1. Flame conditions and compositions of the syngas fuels

\begin{tabular}{|l|l|l|l|l|}
\hline Case & Flame H & Flame HN & Flame HNC1 & Flame HNC2 \\
\hline $\begin{array}{l}\text { Jet diameter } \\
(\mathrm{mm})\end{array}$ & 3.75 & 8.0 & 7.72 & 7.72 \\
\hline $\begin{array}{l}\text { Jet velocity } \\
(\mathrm{m} / \mathrm{s})\end{array}$ & 296.0 & 42.3 & 45.0 & 45.0 \\
\hline $\mathrm{H}_{2} \%$ & 100 & 75 & 30 & 10 \\
\hline $\mathrm{N}_{2} \%$ & 0 & 25 & 30 & 60 \\
\hline $\mathrm{CO} \%$ & 0 & 0 & 40 & 30 \\
\hline
\end{tabular}




\section{Figure Captions}

Fig.1. Flame H: Instantaneous three-dimensional visualisation of the flame temperature with iso-values of (a) $\mathrm{T}=500 \mathrm{~K}$, (b) $\mathrm{T}=1000 \mathrm{~K}$, (c) $\mathrm{T}=1500 \mathrm{~K}$, (d) $\mathrm{T}=2000 \mathrm{~K}$, (e) $\mathrm{T}=2200 \mathrm{~K}$ obtained from LES calculation at $\mathrm{t}=0.05 \mathrm{~s}$.

Fig.2. Flame HN: Instantaneous three-dimensional visualisation of the flame temperature with iso-values of (a) $\mathrm{T}=500 \mathrm{~K}$, (b) $\mathrm{T}=700 \mathrm{~K}$, (c) $\mathrm{T}=1000 \mathrm{~K}$, (d) $\mathrm{T}=1500 \mathrm{~K}$, (e) $\mathrm{T}=2000 \mathrm{~K}$,(f) $\mathrm{T}=2100 \mathrm{~K}$ obtained from LES calculation at $\mathrm{t}=0.2 \mathrm{~s}$.

Fig.3. Flame HNC1: Instantaneous three-dimensional visualisation of the flame temperature with iso-values of (a) $\mathrm{T}=500 \mathrm{~K}$, (b) $\mathrm{T}=700 \mathrm{~K}$, (c) $\mathrm{T}=1000 \mathrm{~K}$, (d) $\mathrm{T}=1500 \mathrm{~K}$, (e) $\mathrm{T}=1700 \mathrm{~K}$, (f) $\mathrm{T}=2000 \mathrm{~K}$ obtained from LES calculation at $\mathrm{t}=0.2 \mathrm{~s}$.

Fig.4. Flame HNC2: Instantaneous three-dimensional visualisation of the flame temperature with iso-values of (a) $\mathrm{T}=500 \mathrm{~K}$, (b) $\mathrm{T}=700 \mathrm{~K}$, (c) $\mathrm{T}=1000 \mathrm{~K}$, (d) $\mathrm{T}=1300 \mathrm{~K}$, (e) $\mathrm{T}=1500 \mathrm{~K}$, (f) $\mathrm{T}=1700 \mathrm{~K}$ obtained from LES calculation at $\mathrm{t}=0.2 \mathrm{~s}$.

Fig.5. Instantaneous two-dimensional contour plots of mixture fraction and flame temperature of syngas flames $\mathrm{HN}, \mathrm{HNC} 1$ and $\mathrm{HNC} 2$ at $\mathrm{t}=0.2 \mathrm{~s}$.

Fig.6. Comparison of mean mixture fraction for flames H, HN and HNC1. Lines denote LES data and symbols denote experimental data.

Fig.7. Comparison of mixture fraction variance for flames $\mathrm{H}, \mathrm{HN}$ and $\mathrm{HNC} 1$. Lines denote LES data and symbols denote experimental data.

Fig.8. Comparison of mean temperature for flames $\mathrm{H}, \mathrm{HN}, \mathrm{HNC1}$ and $\mathrm{HNC} 2$. Lines denote LES data (dashed for HNC2) and symbols denote experimental data.

Fig.9. Comparison of $\mathrm{H}_{2}$ for flames $\mathrm{H}, \mathrm{HN}, \mathrm{HNC1}$ and $\mathrm{HNC} 2$. Lines denote LES data (dashed for HNC2) and symbols denote experimental data.

Fig.10. Comparison of $\mathrm{H}_{2} \mathrm{O}$ for flames $\mathrm{H}, \mathrm{HN}, \mathrm{HNC} 1$ and $\mathrm{HNC} 2$. Lines denote LES data (dashed for HNC2) and symbols denote experimental data.

Fig.11. Comparison of $\mathrm{CO}$ and $\mathrm{CO}_{2}$ for flames $\mathrm{HNC} 1$ and HNC2. Lines denote LES data (dashed for HNC2) and symbols denote experimental data. 


\section{Figures}

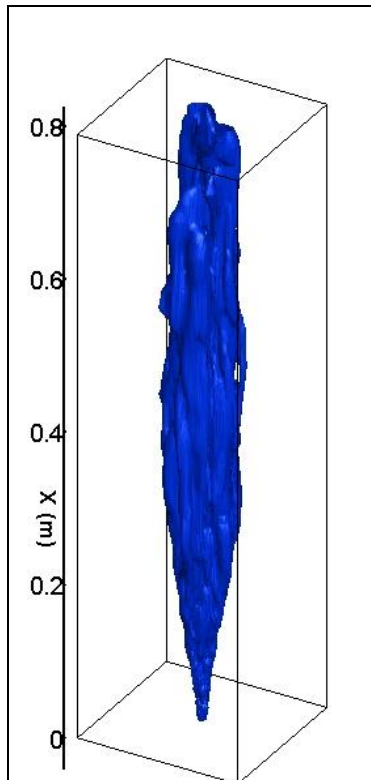

(a)

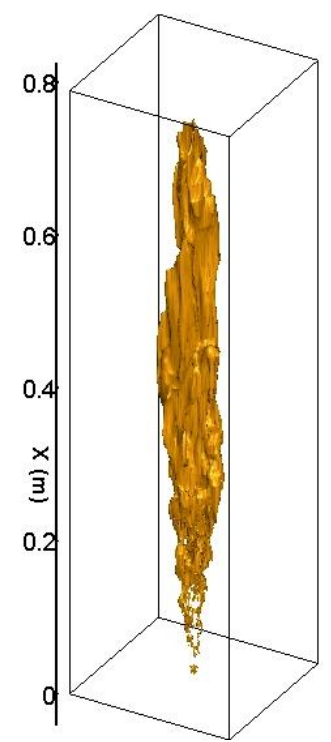

(d)

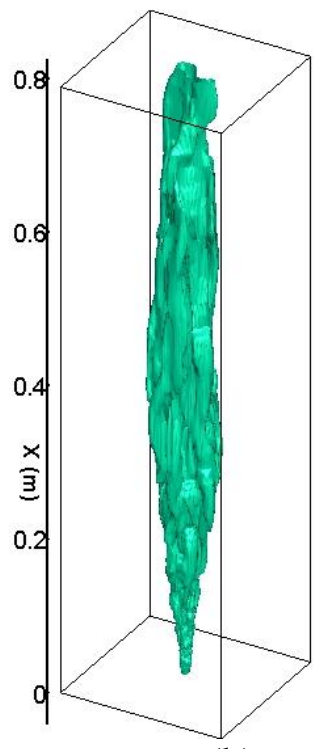

(b)

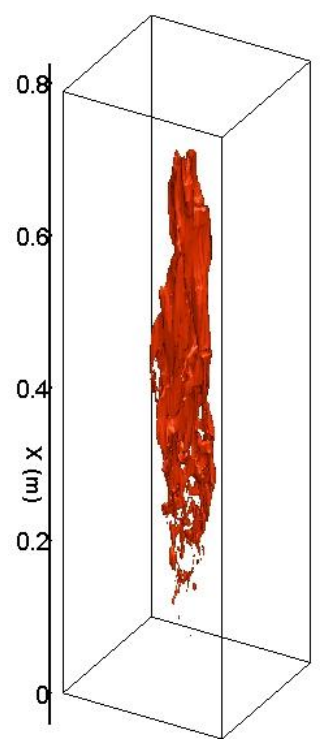

(e)

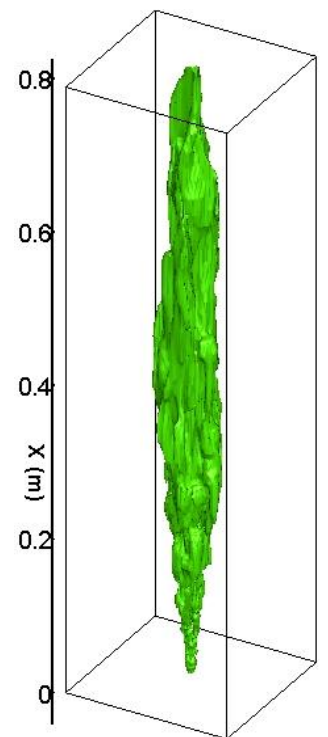

(c)

Fig.1. Flame H: Instantaneous three-dimensional visualisation of the flame temperature with iso-values of (a) $\mathrm{T}=500 \mathrm{~K}$, (b) $\mathrm{T}=1000 \mathrm{~K}$, (c) $\mathrm{T}=1500 \mathrm{~K}$, (d) $\mathrm{T}=2000 \mathrm{~K}$, (e) $\mathrm{T}=2200 \mathrm{~K}$ obtained from LES calculation at $\mathrm{t}=0.05 \mathrm{~s}$. 


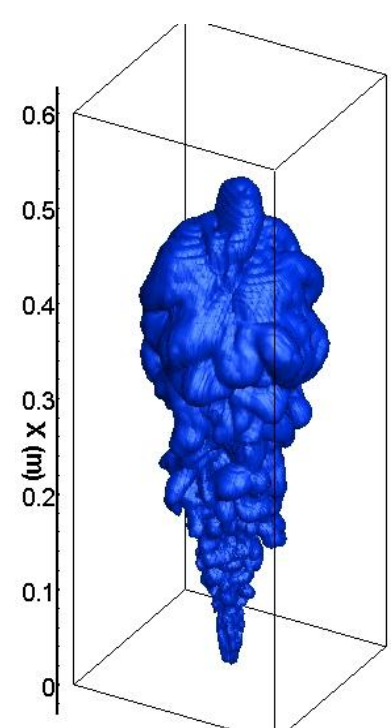

(a)

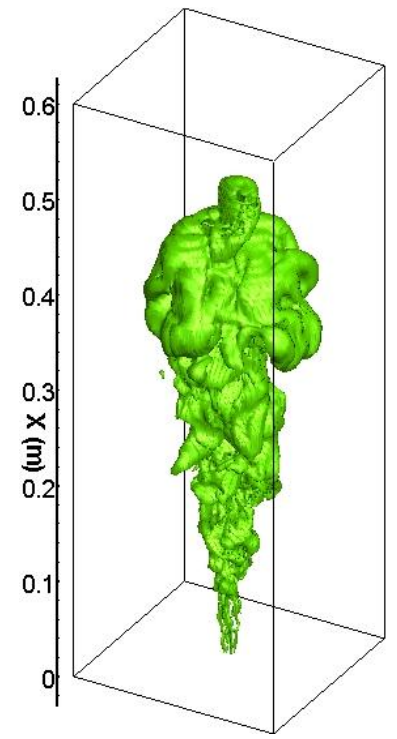

(d)

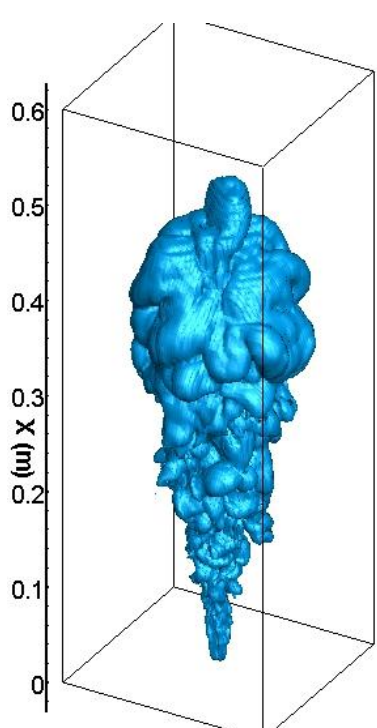

(b)

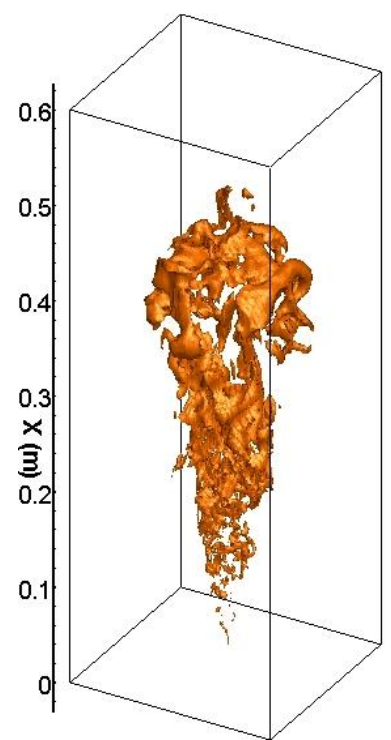

(e)

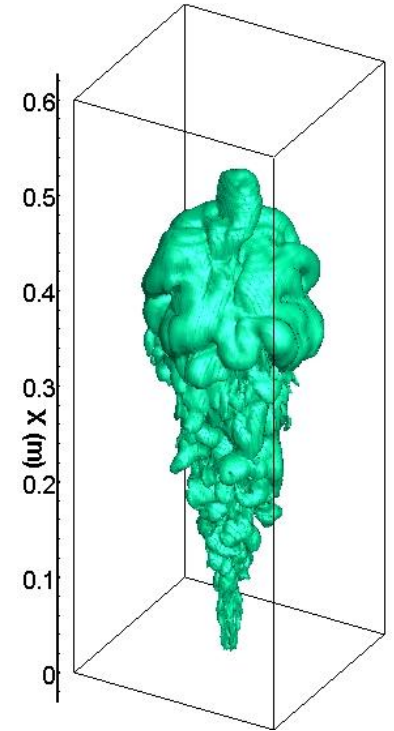

(c)

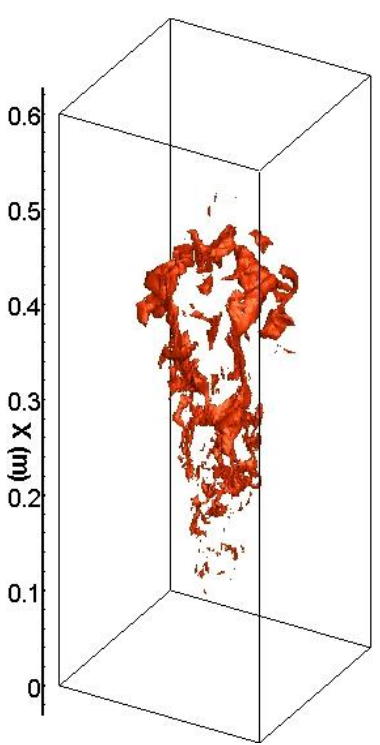

(f)

Fig.2. Flame HN: Instantaneous three-dimensional visualisation of the flame temperature with iso-values of (a) T=500K, (b) T=700K, (c) T=1000K, (d) T=1500K, (e) T=2000K, (f) $\mathrm{T}=2100 \mathrm{~K}$ obtained from LES calculation at $\mathrm{t}=0.2 \mathrm{~s}$. 


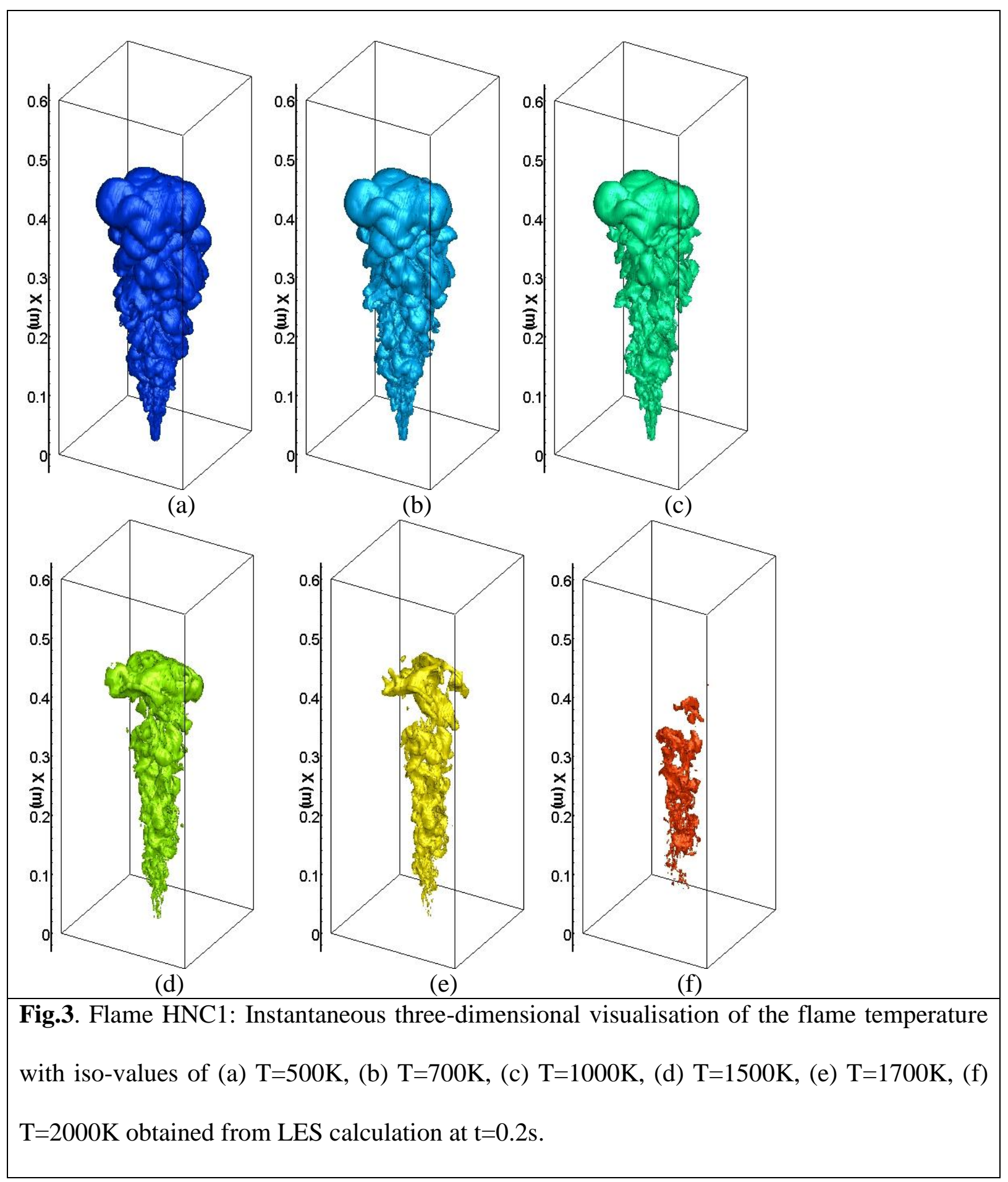




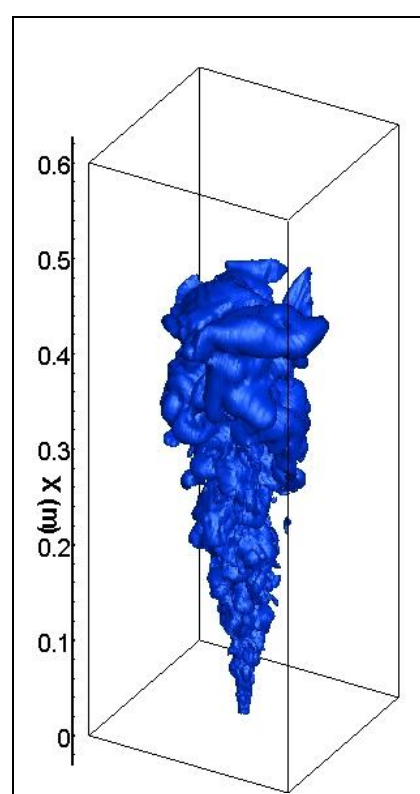

(a)

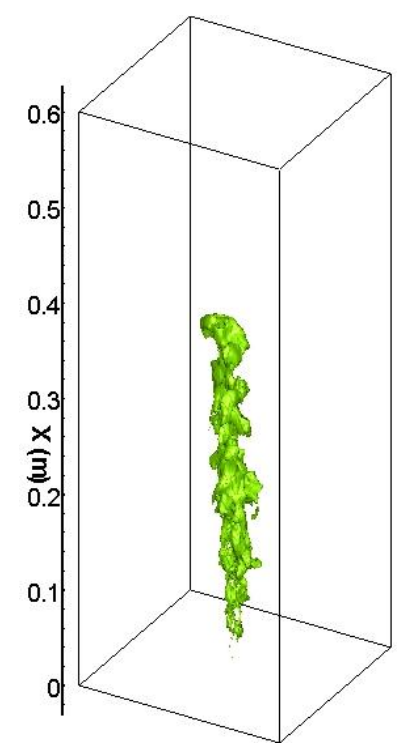

(d)

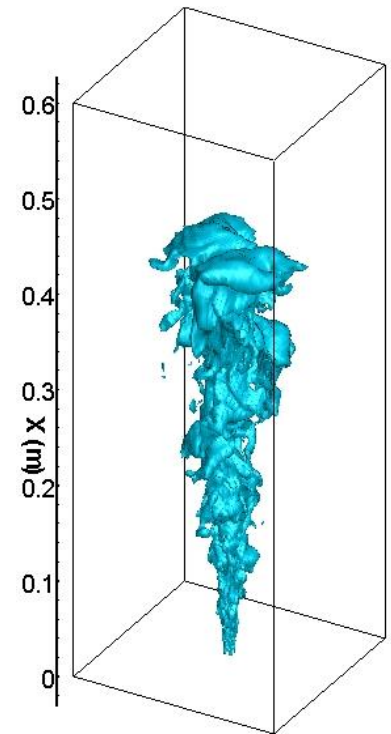

(b)

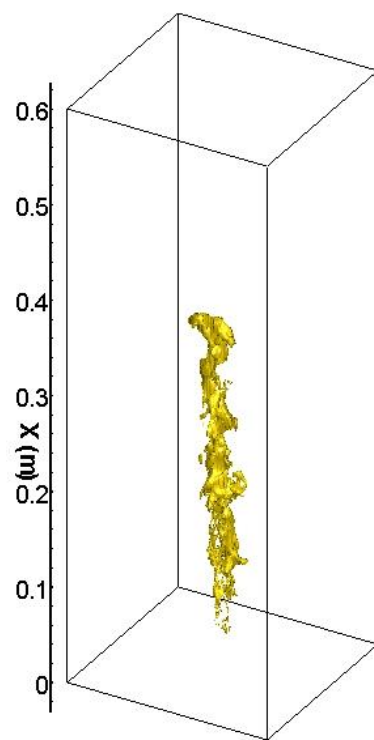

(e)

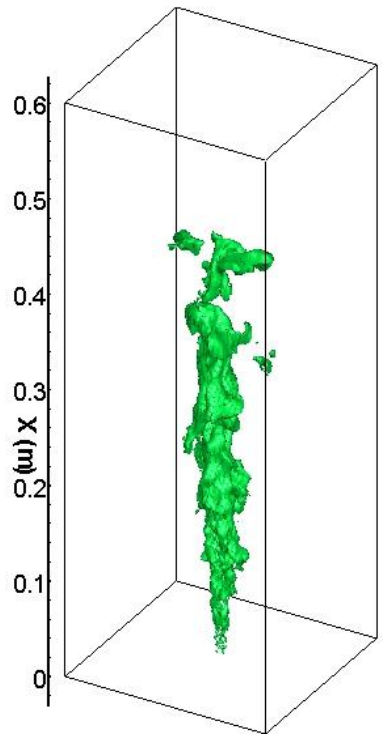

(c)

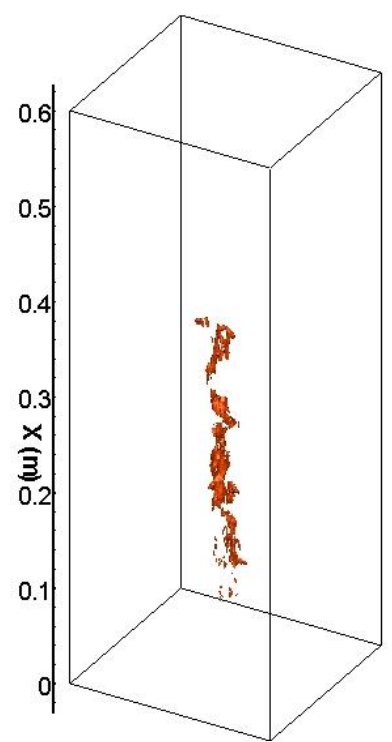

(f)

Fig.4. Flame HNC2: Instantaneous three-dimensional visualisation of the flame temperature with iso-values of (a) $\mathrm{T}=500 \mathrm{~K}$, (b) $\mathrm{T}=700 \mathrm{~K}$, (c) $\mathrm{T}=1000 \mathrm{~K}$, (d) $\mathrm{T}=1300 \mathrm{~K}$, (e) $\mathrm{T}=1500 \mathrm{~K}$, (f) $\mathrm{T}=1700 \mathrm{~K}$ obtained from LES calculation at $\mathrm{t}=0.2 \mathrm{~s}$. 


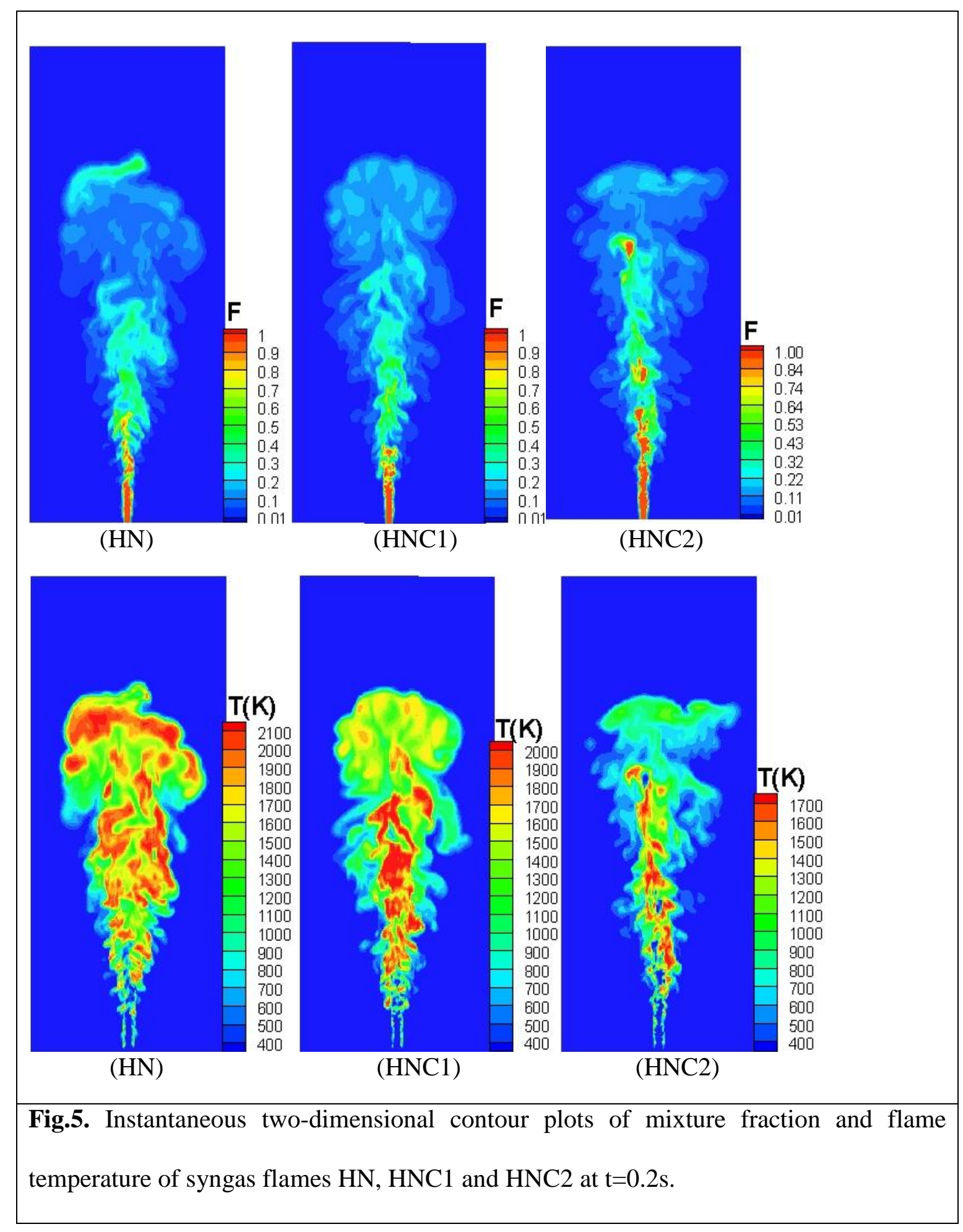




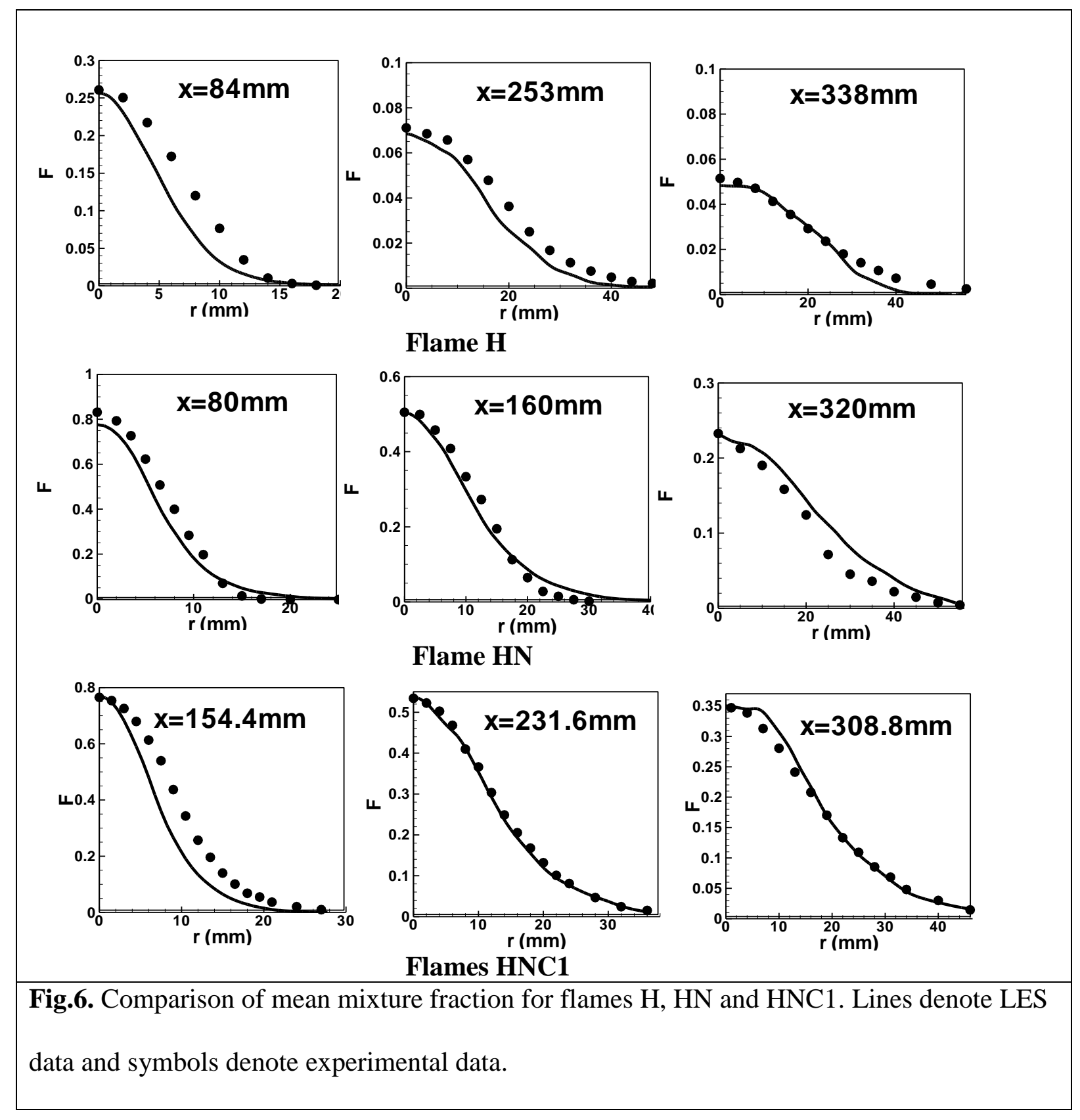




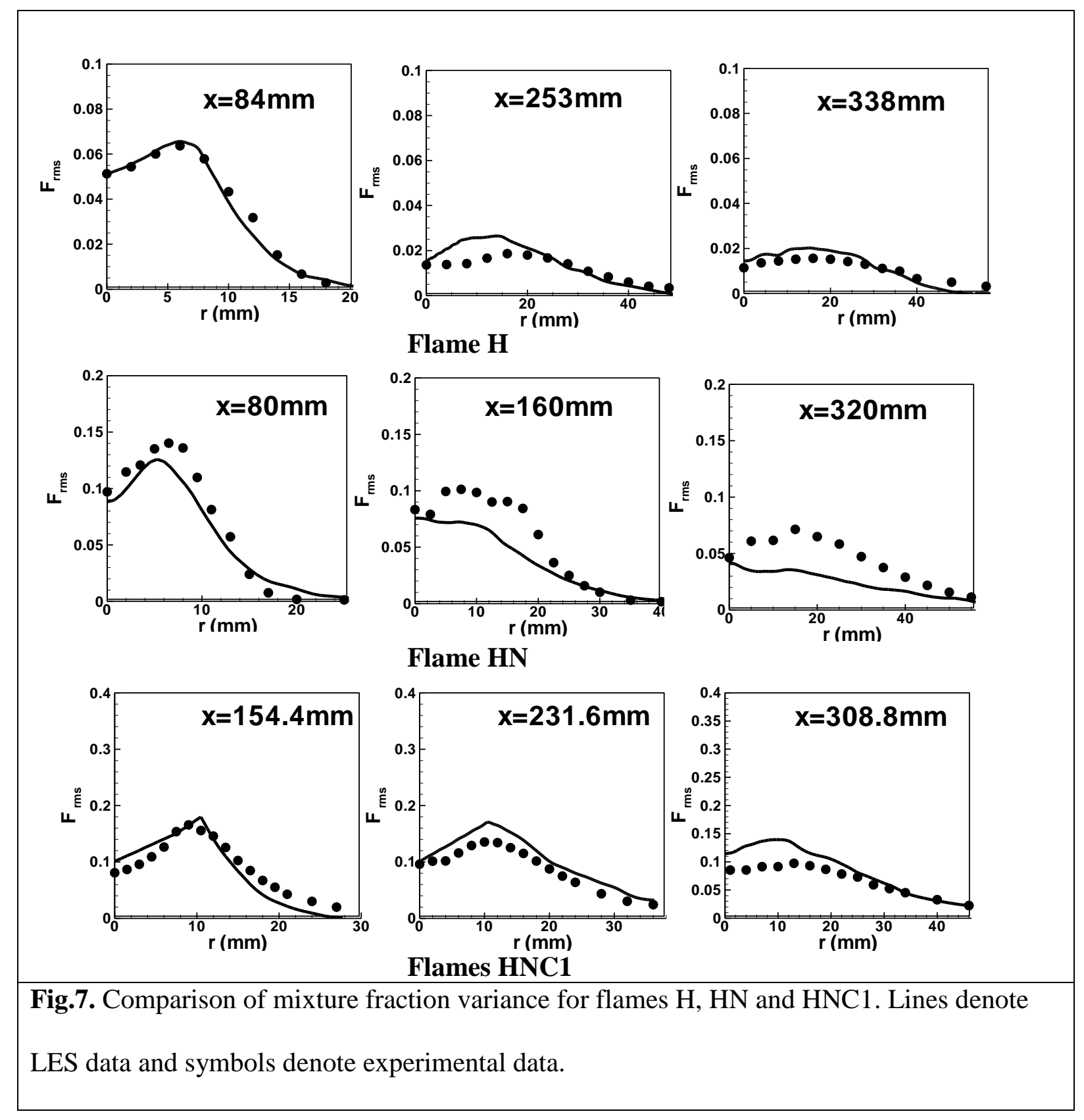




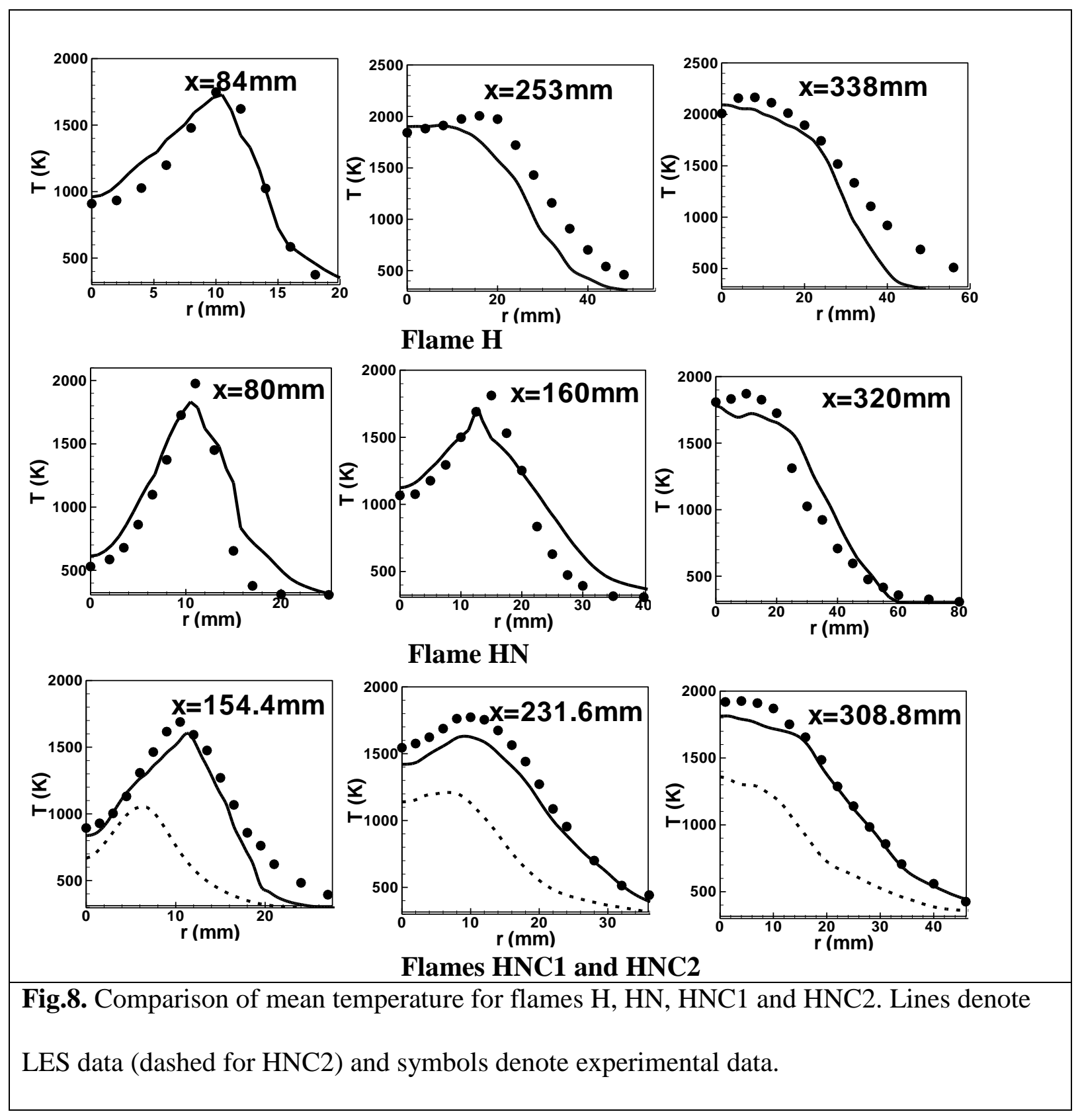




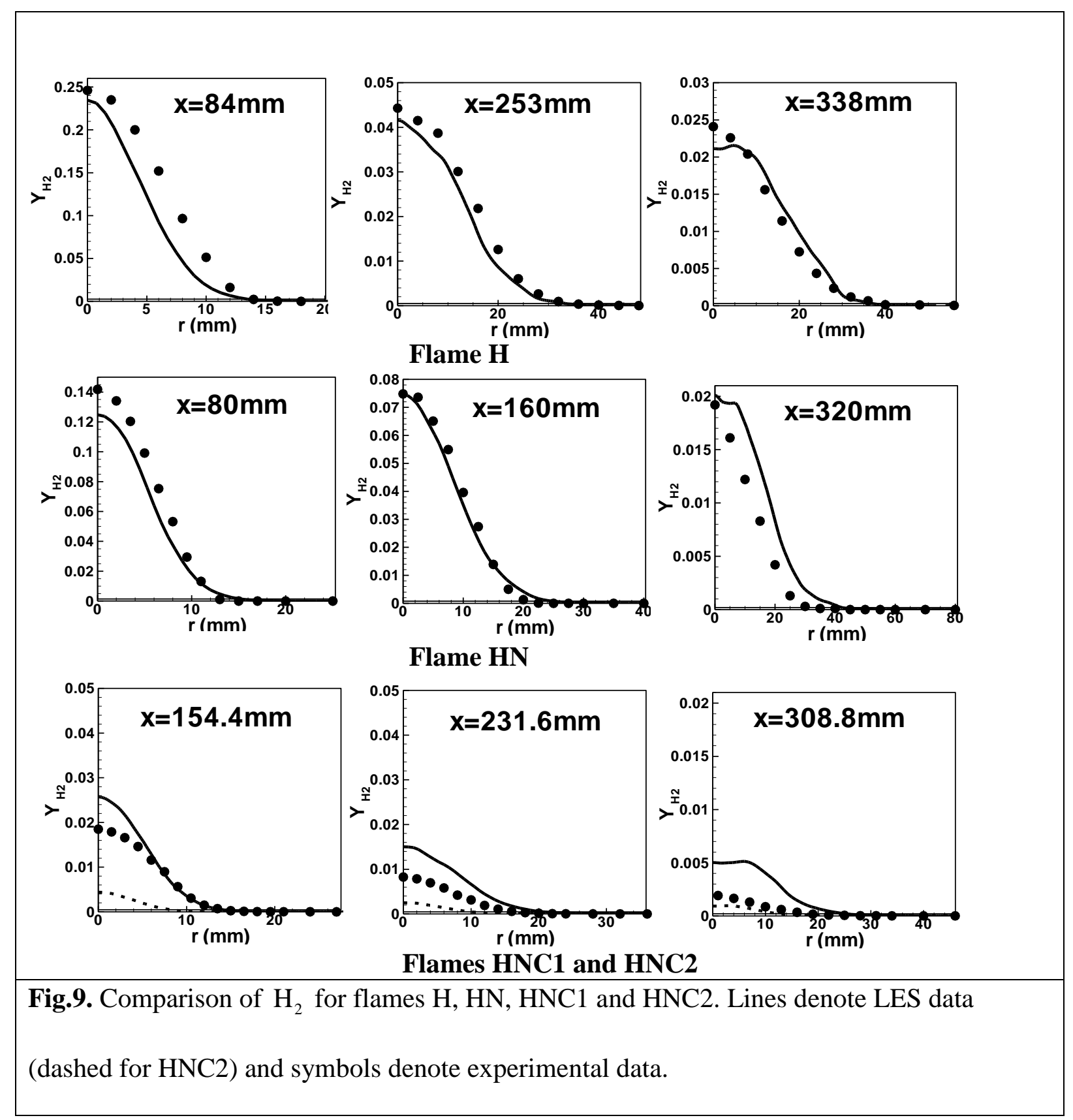




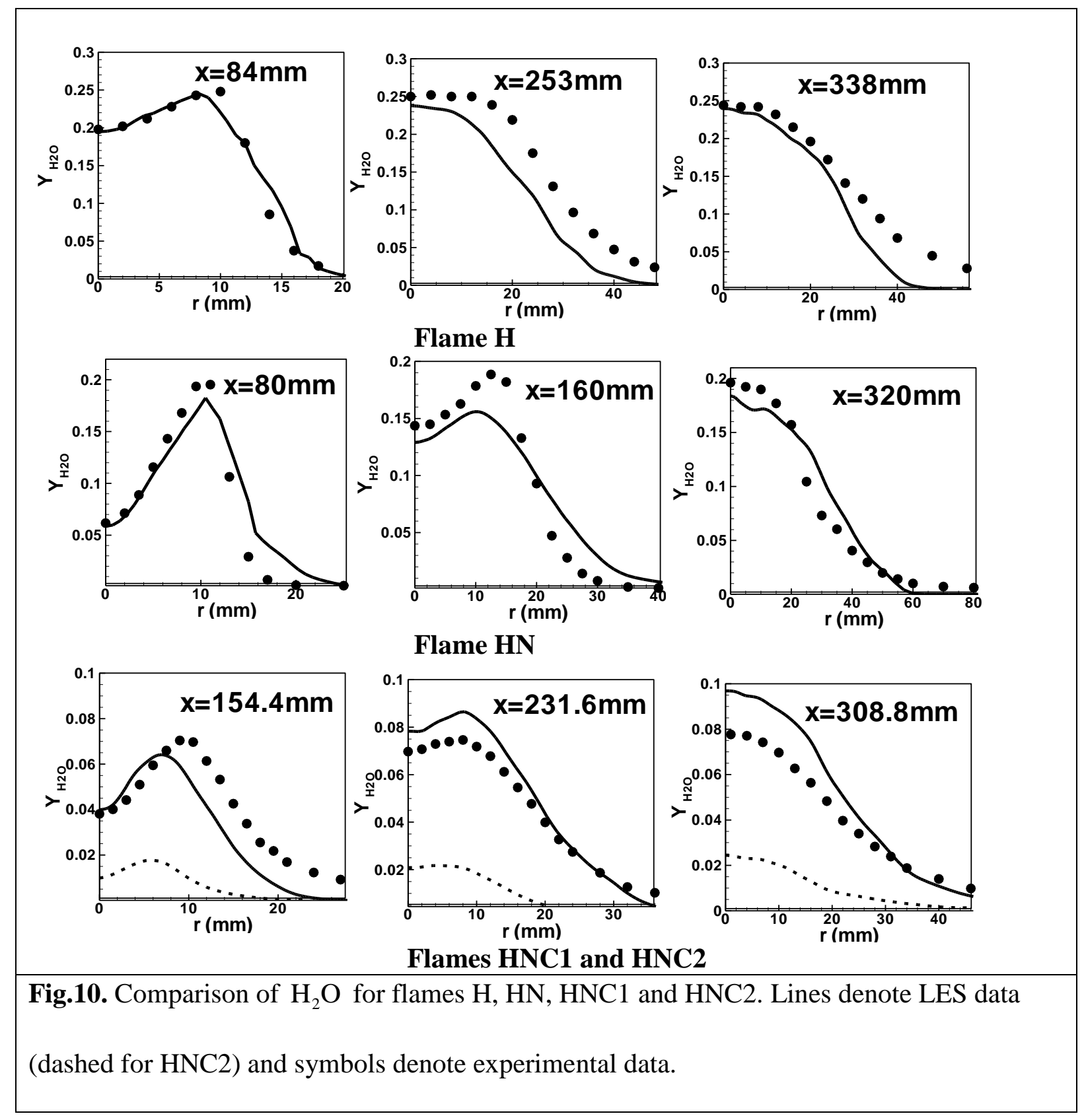




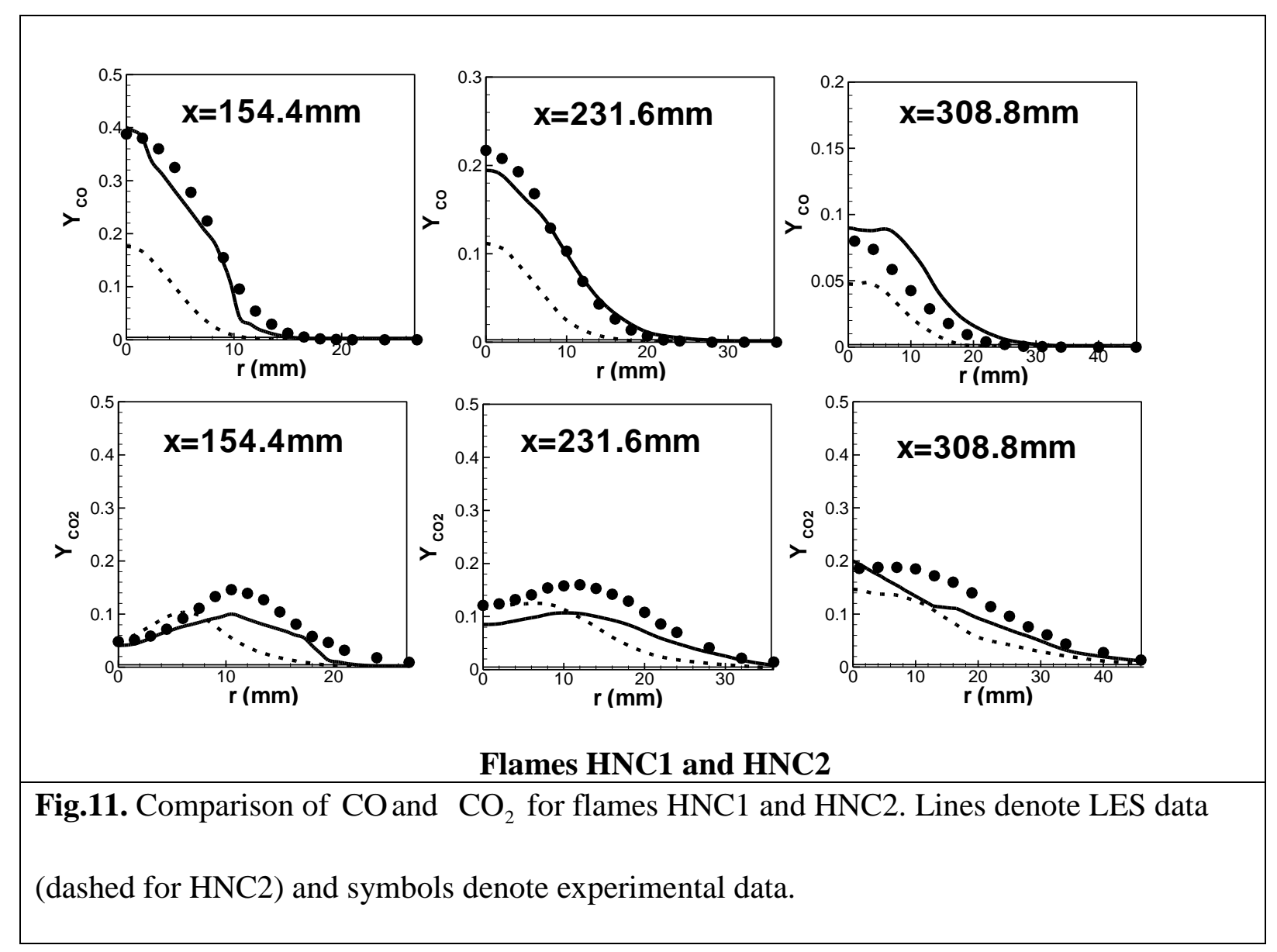

